\title{
The role of mycoplasmas, ureaplasmas and chlamydiae in the genital tract of women presenting in spontaneous early preterm labour
}

\author{
R. F. LAMONT*, D. TAYLOR-ROBINSONt, J. S. WIGGLESWORTH $¥$, P. M. FURRt, R. T. \\ EVANSt and $M$. G. ELDER
}

Institute of Obstetrics and Gynaecology and $¥ D$ Department of Paediatric and Neonatal Medicine, Hammersmith Hospital, London and TDivision of Sexually Transmitted Diseases, MRC Clinical Research Centre, Watford Road, Harrow, Middlesex

\begin{abstract}
Summary. The genital carriage of Ureaplasma urealyticum, Mycoplasma hominis and Chlamydia trachomatis was assessed in 72 women admitted to hospital in spontaneous preterm labour and in 26 women requiring preterm delivery for other reasons who formed a control group. Women in preterm labour significantly more often carried ureaplasmas, had large numbers of $M$. hominis and subsequently developed chorioamnionitis than women in the control group. $M$. hominis, in particular, occurred more frequently and in large numbers in women who had chorioamnionitis associated with ruptured membranes. Genital carriage of the various micro-organisms appeared not to be associated with fetal growth retardation, although subsequent isolation of ureaplasmas from infants was common. It is suggested that mid-second-trimester vaginal specimens should be cultured on a research basis to establish whether these various micro-organisms identify women at risk of labouring preterm.
\end{abstract}

\section{Introduction}

The aetiology of preterm labour is multifactorial (Turnbull and Anderson, 1978) and infection is thought to be one of the precipitating factors (Minkoff, 1983). Genital mycoplasmas have been associated with non-specific vaginitis (bacterial vaginosis) and are considered to be one of the causes of pelvic inflammatory disease (PID) and post-abortal and post-partum fever (Taylor-Robinson and McCormack, 1980a). Furthermore, there is increasing interest in the role of genital mycoplasmas in disorders of reproduction, namely infertility, habitual abortion and stillbirth, low birth weight and prematurity (Taylor-Robinson and McCormack, 1980 b). Genital immunotypes of Chlamydia trachomatis are a cause of cervicitis and PID, with its associated infertility, and are candidates for causal roles in the aforementioned reproductive problems (Taylor-Robinson and Thomas, 1980). To assess the importance of Ureaplasma urealyticum, Mycoplasma hominis and chlamydiae in perinatal disease, we have conducted

Received 14 Nov. 1986; accepted 31 Dec. 1986.

* Present address to which requests for offprints should be sent: Department of Human Reproduction and Obstetrics, Princess Anne Hospital, Coxford Road, Southampton SO9 4HA. a prospective study of the occurrence of these micro-organisms in the lower genital tract of women presenting in spontaneous early preterm labour compared to their occurrence in a group of pregnant women not in labour but at the same gestational stage.

\section{Subjects studied and methods}

\section{Subjects}

Ninety-eight women were investigated and informed consent was obtained from all of them. They consisted of a study group of 72 patients and a control group of 26 patients. The study group comprised women who presented in labour between 26 weeks and 33 completed weeks of pregnancy. The control group comprised women who were not in labour but who required abdominal delivery before 34 weeks of gestation because of some fetal or maternal complication of pregnancy.

There were no differences between the study and control groups with respect to age, race, social class, or mean gestational age (table I), but more of the patients in the control group were primigravidae and had smaller babies, and whereas only $28(39 \%)$ of the patients in the study group had intact membranes at the time of investigation, all those in the control group had intact membranes.

Neonatal infection was diagnosed if there was a 
Table I. Comparison of characteristics of patients comprising the study and control groups

Number ( $\%$ ) of patients (or value) in indicated category

\begin{tabular}{lrc}
\cline { 2 - 3 } Characteristic & Study group (72) & Control group (26) \\
\hline Mean age (SD) & $26 \cdot 6(6)$ & $27 \cdot 3(5)$ \\
Race & & \\
Caucasian & $49(68 \%)$ & $20(78 \%)$ \\
Asian & $8(11 \%)$ & $5(19 \%)$ \\
Negro & $16(22 \%)$ & $1(4 \%)$ \\
Social class & & \\
I or II & $15(21 \%)$ & $6(23 \%)$ \\
III or IV & $45(62 \%)$ & $17(65 \%)$ \\
V or unclassified & $13(18 \%)$ & $3(12 \%)$ \\
Parity & & \\
Primigravidae & $16(22 \%)$ & $13(50 \%)^{*}$ \\
Primiparae & $31(43 \%)$ & $16(62 \%)$ \\
Multiparae & $41(57 \%)$ & $10(38 \%)$ \\
Mean gestational age (SD) $($ days) & \\
On entry to trial & $211(16)$ & $222(15)$ \\
At delivery & $215(18)$ & $223(15)$ \\
Mean birthweight (SD) (g) & & \\
& $1590(510)$ & $1383(363)^{*}$ \\
& &
\end{tabular}

$* \mathrm{p}=<0.02$.

positive bacterial culture of neonatal blood, or if there were signs of infection (respiratory distress, early jaundice, apnoea, neutropenia or elevated immature white cell count) in the first $48 \mathrm{~h}$ of life sufficient for the infant to receive a 5-day course of antibiotics.

\section{Laboratory methods}

Specimens were collected in a similar manner from subjects in the study and control groups by one of the investigators (RFL). Specimens from the study patients were taken at the first vaginal examination after admission in preterm labour and those from control patients in the $24 \mathrm{~h}$ before elective delivery. A high vaginal specimen to be examined for ureaplasmas and $M$. hominis was taken with a cotton-wool swab which was expressed in $1.5 \mathrm{ml}$ of mycoplasmal transport medium (Taylor-Robinson and Furr, 1981); this was deemed to be a ten-fold dilution. Polypropylene swabs to obtain surface epithelial cells were used to take specimens from the endocervix for chlamydial culture and were expressed in sucrose-phosphate transport medium (2SP) (Thomas et al., 1977). All specimens in transport medium were stored in liquid nitrogen and examined as a group at the end of the study. The genital mycoplasmas were isolated and identified with media and procedures described previously (Taylor-Robinson and Furr, 1981) and the numbers of these organisms (titres) are expressed as colour-changing units $(\mathrm{ccu}) / \mathrm{ml}$ of transport medium.
Chlamydiae were sought by inoculation of specimens into cycloheximide-treated McCoy cell cultures, as described previously (Thomas et al., 1977).

Specimens for histological examination were taken as soon as possible after delivery. Umbilical cord (about $1 \mathrm{~cm}$ in length), villous plate (about $2 \mathrm{~cm}^{3}$ ) and membranes (a $3 \mathrm{~cm} \times 0.5 \mathrm{~cm}$ strip from the edge of the membrane rupture site to the placental edge) were obtained and placed in formal saline. Smaller samples were taken from these fixed specimens for histological processing and staining with haemotoxylin and eosin. At the time of examination, neither the histopathologist nor the microbiologist knew whether the tissues had been obtained from a member of the study group or of the control group. Chorioamnionitis was diagnosed if there was histological evidence of polymorphonuclear leukocyte infiltration into any of six areas of the cord, membranes or placenta. These areas were the cord vessels, the extraplacental membranes, the chorionic plate, the subchorial lake of the villous plate, the villi and the intervillous space. Histological data were available for 58 patients.

The statistical significance of the data was calculated by either Students $t$ test or the $\chi^{2}$ test with Yates's correction for small numbers. Only those probability values which reach statistical significance $(\mathrm{p}<0.05)$ are quoted.

\section{Results}

\section{Isolation of micro-organisms from patients and controls}

Ureaplasmas were isolated from $62(86 \%)$ of the patients in the study group and from $12(46 \%)$ of those in the control group, a difference which is significant $(\mathrm{p}<0 \cdot 01)$. M. hominis was isolated from $17(24 \%)$ of the study patients and from $2(8 \%)$ of the control patients, a difference which is not significant. However, these organisms in large numbers $\left(\geqslant 10^{5} \mathrm{ccu}\right)$ were detected in $13(18 \%)$ of the study patients but in none of the control patients $(p<0.05)$.

Chlamydiae were isolated from $5(8 \%)$ of 63 patients in the study group whose specimens could be validly tested, but from none of 21 in the control group. Specimens from 9 of the patients in the study group could not be validly tested because they destroyed the McCoy-cell monolayers.

\section{Relation between carriage of micro-organisms and interval since coitus}

The carriage of ureaplasmas, $M$. hominis or chlamydiae in patients in the study group who gave a history of coitus $<48 \mathrm{~h}$ or $<7$ days, respectively, before study entry was similar to that in those in whom coitus did not take place during these times. 
Table II. Isolation of micro-organisms from study patients in relation to the state of the membranes

\begin{tabular}{|c|c|c|c|c|c|c|}
\hline \multirow[b]{3}{*}{ Micro-organism } & \multicolumn{3}{|c|}{ Intact membranes } & \multicolumn{3}{|c|}{ Ruptured membranes } \\
\hline & \multirow{2}{*}{$\begin{array}{l}\text { Number }(\%) \text { of } \\
\text { patients positive }\end{array}$} & \multicolumn{2}{|c|}{$\begin{array}{l}\text { Number of organisms isolated } \\
(\mathrm{ccu} / \mathrm{ml})\end{array}$} & \multirow{2}{*}{$\begin{array}{l}\text { Number }(\%) \text { of } \\
\text { patients positive }\end{array}$} & \multicolumn{2}{|c|}{$\begin{array}{l}\text { Number of organisms isolated } \\
\qquad(\mathrm{ccu} / \mathrm{ml})\end{array}$} \\
\hline & & range & geometric mean & & range & geometric mean \\
\hline U. urealyticum & $22(79 \%)$ & $10^{1}-10^{6}$ & $10^{4 \cdot 2}$ & $36(81 \%)$ & $10^{1}-10^{7}$ & $10^{4 \cdot 4}$ \\
\hline M. hominis & $7(25 \%)$ & $10^{2}-10^{7}$ & $10^{4 \cdot 8}$ & $10(23 \%)$ & $10^{3}-10^{7}$ & $10^{5 \cdot 2}$ \\
\hline C. trachomatis & $1(4 \%)$ & $\ldots$ & $\ldots$ & $4(10 \%)$ & $\ldots$ & $\ldots$ \\
\hline
\end{tabular}

Relation between carriage of micro-organisms and membrane rupture

As shown in table II, the proportions of study patients with and without ruptured membranes who were colonised by ureaplasmas, $M$. hominis or chlamydiae were not different, nor were the numbers (geometric mean $\mathrm{ccu} / \mathrm{ml}$ ) of the genital mycoplasmas in women with and without ruptured membranes.

\section{Relation between carriage of micro-organisms and chorioamnionitis}

Histological examination of tissues was undertaken in 58 patients. Patients in the control group did not have ruptured membranes and only two had chorioamnionitis. On the other hand, $44(61 \%)$ of the study patients had ruptured membranes and chorioamnionitis was found two to three times more often in them than in study patients with intact membranes. Irrespective of membrane rupture, the micro-organisms were found about as frequently in study patients who did not have chorioamnionitis as in those who did (table III), although the number of $M$. hominis organisms in the chorioamnionitis-positive group was larger (geometric mean $10^{5.3} \mathrm{ccu} / \mathrm{ml}$ ) than in the chorioamnionitis-negative group (geometric mean $10^{3 \cdot 7} \mathrm{ccu} / \mathrm{ml}$ ).

In women who had ruptured membranes and who subsequently developed chorioamnionitis, ureaplasmas were present in $15(75 \%)$ of $20, M$. hominis in $8(40 \%)$ of 20 and chlamydiae in $1(6 \%)$ of 17 . In those who had ruptured membranes and who did not develop chorioamnionitis, ureaplasmas were present in $7(88 \%)$ of $8, M$. hominis in $1(13 \%)$ of 8 and chlamydiae in $1(11 \%)$ of 9 . Although the difference in carriage rates for $M$. hominis did not reach statistical significance, it was found three times more often in women who had chorioamnionitis than in those who did not.

\section{Relation between carriage of micro-organisms and mean birthweight and gestational age}

As shown in table IV, the mean birthweight and mean gestational age of infants born to mothers who were colonised by ureaplasmas, $M$. hominis or chlamydiae were not significantly different from those of infants born to mothers who were not

Table III. Carriage of micro-organisms in relation to occurrence of chorioamnionitis

Indicated micro-organisms in

\begin{tabular}{|c|c|c|c|c|c|c|c|}
\hline \multirow[b]{3}{*}{ Chorioamnionitis } & \multirow[b]{3}{*}{ Micro-organism } & \multirow{2}{*}{\multicolumn{3}{|c|}{ Patients in study group }} & & & \\
\hline & & & & & \multicolumn{3}{|c|}{ Patients in control group } \\
\hline & & $\begin{array}{l}\text { Number } \\
\text { examined }\end{array}$ & $\begin{array}{l}\text { Number } \\
\text { positive }\end{array}$ & $\begin{array}{l}\text { Percentage } \\
\text { positive }\end{array}$ & $\begin{array}{l}\text { Number } \\
\text { examined }\end{array}$ & $\begin{array}{l}\text { Number } \\
\text { positive }\end{array}$ & $\begin{array}{l}\text { Percentage } \\
\text { positive }\end{array}$ \\
\hline \multirow[t]{3}{*}{ Present } & U. urealyticum & 22 & 16 & 73 & 2 & 2 & 100 \\
\hline & M. hominis & 22 & 8 & 36 & 2 & 0 & 0 \\
\hline & C. trachomatis & 17 & 1 & 6 & 2 & 0 & 0 \\
\hline \multirow[t]{3}{*}{ Absent } & U. urealyticum & 12 & 10 & 83 & 19 & 7 & 37 \\
\hline & M. hominis & 12 & 3 & 25 & 19 & 2 & 11 \\
\hline & C. trachomatis & 13 & 1 & 8 & 16 & 0 & 0 \\
\hline
\end{tabular}


Table IV. Birthweight and gestational age in relation to maternal colonisation

\begin{tabular}{|c|c|c|c|c|}
\hline \multirow[b]{2}{*}{ Micro-organism } & \multicolumn{2}{|c|}{$\begin{array}{c}\text { Mean birthweight* (SD) when micro- } \\
\text { organism was }\end{array}$} & \multicolumn{2}{|c|}{$\begin{array}{c}\text { Mean gestation* at birth (SD) when micro- } \\
\text { organism was }\end{array}$} \\
\hline & present & absent & present & absent \\
\hline $\begin{array}{l}\text { U. urealyticum } \\
\text { M. hominis } \\
\text { C. trachomatis }\end{array}$ & $\begin{array}{l}1835(761) \mathrm{g} \\
1998(805) \mathrm{g} \\
1445(261) \mathrm{g}\end{array}$ & $\begin{array}{l}1693(634) \mathrm{g} \\
1747(716) \mathrm{g} \\
1834(798) \mathrm{g}\end{array}$ & $\begin{array}{l}225(29) \text { days } \\
226(28) \text { days } \\
213(10) \text { days }\end{array}$ & $\begin{array}{l}216(21) \text { days } \\
223(29) \text { days } \\
224(30) \text { days }\end{array}$ \\
\hline
\end{tabular}

* None of the differences shown is statistically significant.

colonised by these micro-organisms. Infants whose mothers were colonised by ureaplasmas had a mean birthweight of $1835( \pm 761) \mathrm{g}$, whereas those born to women who were colonised by both ureaplasmas and $M$. hominis were even heavier $(2021 \pm 854 \mathrm{~g})$.

\section{Relation between maternal carriage of micro- organisms and perinatal infection}

Specimens were obtained from 29 infants. Of 19 women carrying ureaplasmas, six of their infants were also colonised. Two infants were found to be colonised by ureaplasmas although the organisms were not recovered from the mothers. Five women were colonised by $M$. hominis but none of their infants was infected. One woman was colonised by chlamydiae but they were not isolated from her infant. There were 11 perinatal and neonatal deaths, all infants delivered to mothers in the preterm labour group. None of the mothers carried $M$. hominis, one was colonised by chlamydiae and nine were colonised by ureaplasmas.

\section{Discussion}

In this prospective study, we attempted to determine the role of ureaplasmas, $M$. hominis and chlamydiae in spontaneous preterm labour. Ninetyeight consecutive patients were examined, there being three times more patients with preterm labour than those serving as controls. This reflects the difficulty of obtaining such control patients even in a referral centre where six times the national average of very low birthweight babies are delivered. Despite the small numbers, women admitted in preterm labour at less than 34 weeks were found to have a significantly increased prevalence of ureaplasmal carriage and larger numbers of $M$. hominis organisms than patients in the control group. Isolation of chlamydiae was unique to the study group. The prevalence of genital mycoplasmas in the control group was almost identical to that seen in normal antenatal patients of similar social class in a study at a district general hospital in the same region in which the current study was conducted-ureaplasmas, $M$. hominis and chlamydiae being present in $42 \%, 9 \%$ and none of the normal subjects, respectively (Ross et al., 1981). This suggests that the figures presented for the prevalence of micro-organisms in the control group in the current study are real and that the difference between the control and study groups is not spurious. This difference in the prevalence of microorganisms could reflect differences in sexual behaviour, such as promiscuity, which we were unable to determine. The findings, however, appeared to be independent of recent coitus.

The relationships between maternal carriage of the various micro-organisms, the rupture of membranes and the occurrence of chorioamnionitis are complex but may be expressed in the following way. Rupture of membranes seen only in patients in the preterm labour group was apparently not associated with the presence of the genital microorganisms; they were distributed evenly among those who did and did not have ruptured membranes. If the micro-organisms are not a direct cause of membrane rupture, are they responsible for chorioamnionitis? Chorioamnionitis occurred more often in patients with ruptured membranes and it is reasonable to surmise that the microorganisms could stimulate an inflammatory response once they had gained access to the membranes. The evidence points to the possibility of $M$. hominis being involved. Although the distribution of the micro-organisms between patients who did and did not have chorioamnionitis was not different, $M$. hominis organisms were present in larger numbers in those who had chorioamnionitis and were present more often than the other organisms in patients who had chorioamnionitis associated with ruptured membranes.

Evidence linking ureaplasmas and $M$. hominis with low birthweight is contradictory. Braun et al. 
(1971) found that women who were colonised by ureaplasmas gave birth to infants with significantly lower birthweights than did women who were not colonised. Furthermore, the effect of colonisation by ureaplasmas and $M$. hominis was greater than that of ureaplasmas alone. On the other hand, other workers, including Ross et al. (1981), have not found such an association. The current study was not initiated with this aspect in mind and the number of patients examined may be insufficient to detect any association. However, neither ureaplasmas nor $\boldsymbol{M}$. hominis was found more frequently in mothers who gave birth to low-weight babies than in those who did not. It is well known that maternal carriage of these micro-organisms leads to colonisation of the newborn and, in this study, $32 \%$ and $20 \%$ of the infants were colonised by ureaplasmas and $M$. hominis, respectively. Whether they were in any way responsible for the neonatal morbidity that was seen is, of course, debatable.

The finding of a high prevalence of the microorganisms in women who labour preterm does not necessarily mean a causal relationship. However, a mechanism whereby abnormal genital colonisation might cause preterm labour has been postulated. Bejar et al. (1981) have shown that many organisms associated with intrauterine sepsis produce phospholipase $A_{2}$, an enzyme that is responsible for the release of free arachidonic acid from cell membranes. Arachidonic acid is the obligate precursor of prostaglandins and these may be responsible for the initiation of labour. Furthermore, using an in-

\section{REFERENCES}

Bejar R, Curbelo V, Davis C, Gluck L 1981 Premature labour. II. Bacterial sources of phospholipase. Obstetrics and Gynecology 57:479-482.

Braun P et al. 1971 Birth weight and genital mycoplasmas in pregnancy. New England Journal of Medicine 284: 167-171.

Lamont R F, Rose M, Elder M G 1985 Effect of bacterial products on prostaglandin $\mathrm{E}$ production by amnion cells. Lancet 2: 1331-1333.

Minkoff H 1983 Prematurity: infection as an etiologic factor. Obstetrics and Gynecology 62: 137-144.

Minkoff $\mathrm{H}$ et al. $1984 \mathrm{Risk}$ factors for prematurity and premature rupture of membranes: a prospective study of vaginal flora in pregnancy. American Journal of Obstetrics and Gynecology 150: $965-972$.

Newcombe R G, Chalmers I 1981 Assessing the risk of preterm labour. In: Elder M G, Hendricks C H (eds) Preterm labor. Butterworths, London, pp 47-60.

Ross J M, Furr P M, Taylor-Robinson D, Altman D G, Coid C R 1981 The effect of genital mycoplasmas on human foetal vitro model, Lamont et al.(1985) have demonstrated a rise in the concentration of prostaglandin $E$ in amnion cells in response to bacterial products. This postulated mechanism of preterm labour stimulation assumes that the micro-organisms or their products are anatomically in such a position to bring about these effects, which is possible if they are in the high vagina or cervix. At a more practical level, the question arises as to what our findings might imply. Many scores have been devised to predict preterm labour, but have proved largely unhelpful because of the large number of false positives (Newcombe and Chalmers, 1981). Recently Minkoff et al. (1984) carried out a prospective study of the vaginal flora of 233 pregnant women. They found that women who were infected by ureaplasmas began preterm labour significantly more frequently than those who were not infected. This observation, together with our findings, suggests that taking high vaginal swabs in the middle of the second trimester might identify a group of patients at risk of labouring preterm, and that by treating such women with appropriate antibiotics the occurrence of subsequent preterm labour and chorioamnionitis might be reduced. The idea of establishing this point by undertaking such a study in which the existence of $M$. hominis organisms in large numbers only is used as a marker of preterm labour is attractive. This would diminish the magnitude of the laboratory work associated with such a study and at the same time define better the role of $M$. hominis.

growth. British Journal of Obstetrics and Gynaecology 88: 749-755.

Taylor-Robinson D, Furr P M 1981 Recovery and identification of human genital tract mycoplasmas. Israel Journal of Medical Sciences 17:648-653.

Taylor-Robinson D, McCormack W M 1980a The genital mycoplasmas. Part I. New England Journal of Medicine 302: 1003-1010.

Taylor-Robinson D, McCormack W M $1980 \mathrm{~b}$ The genital mycoplasmas. Part II. New England Journal of Medicine 302: 1063-1067.

Taylor-Robinson D, Thomas B J 1980 The role of Chlamydia trachomatis in genital-tract and associated diseases. Journal of Clinical Pathology 33: 205-233.

Thomas B J, Evans R T, Hutchinson G R, Taylor-Robinson D 1977 Early detection of chlamydial inclusions combining the use of cycloheximide-treated McCoy cells and immunofluorescence staining. Journal of Clinical Microbiology 6:285-292.

Turnbull A C, Anderson A B M 1978 Preterm labor. In: Scarpelli E M, Cosmi E V (eds) Reviews in perinatal medicine, vol 2. Raven Press, New York, pp 103-142. 